\title{
DDOST, PRKCSH and LGALS3, which encode AGE-receptors 1, 2 and 3, respectively, are not associated with diabetic nephropathy in type 1 diabetes
}

\author{
A. Hoverfelt $\cdot$ R. Sallinen • J. M. Söderlund • \\ C. Forsblom • K. Pettersson-Fernholm • \\ M. Parkkonen • P.-H. Groop • M. Wessman • \\ on behalf of the FinnDiane Study Group
}

Received: 30 December 2009/Accepted: 23 March 2010/Published online: 21 May 2010

(C) The Author(s) 2010. This article is published with open access at Springerlink.com

\begin{abstract}
Aims/hypothesis The AGE receptors 1, 2 and 3, which are encoded by DDOST, PRKCSH and LGALS3, respectively, may be involved in the pathogenesis of diabetic complications. We sought to find out whether these genes are associated with diabetic nephropathy, cardiovascular disease and type 1 diabetes or related quantitative traits.

Methods Using the Tagger program, we selected 28 single nucleotide polymorphisms (SNPs) based on the HapMap Centre d'Etude du Polymorphisme (Utah residents with northern and western European ancestry) data. The SNPs were genotyped in 2,719 Finnish patients with type 1 diabetes and tested for association with diabetic nephropathy (821 cases, 1,060 controls), cardiovascular disease and related quantitative traits. For association analysis
\end{abstract}

Electronic supplementary material The online version of this article (doi:10.1007/s00125-010-1771-3) contains supplementary material, which is available to authorised users.

A. Hoverfelt $\cdot$ R. Sallinen · J. M. Söderlund · C. Forsblom •

K. Pettersson-Fernholm • M. Parkkonen · P.-H. Groop $(\bowtie) \cdot$

M. Wessman

Folkhälsan Institute of Genetics, Folkhälsan Research Center,

Biomedicum Helsinki, University of Helsinki,

P.O. Box 63, Haartmaninkatu 8,

FI-00014 Helsinki, Finland

e-mail: per-henrik.groop@helsinki.fi

C. Forsblom · K. Pettersson-Fernholm • P.-H. Groop

Division of Nephrology, Department of Medicine,

Helsinki University Central Hospital,

Helsinki, Finland

M. Wessman

Institute for Molecular Medicine Finland FIMM,

University of Helsinki,

Helsinki, Finland with type 1 diabetes, 703 non-diabetic control participants were genotyped.

Results We found evidence of genotype association between diabetic nephropathy and the SNPs rs2170336 in DDOST $(p=0.03), \mathrm{rs} 311788$ in PRKCSH $(p=0.04)$ and $\mathrm{rs} 311778$ in PRKCSH $(p=0.02)$. However, these associations did not reach the significance limit of 0.0008 adjusted for multiple testing. None of the DDOST, PRKCSH or LGALS3 SNPs were associated with quantitative traits related to diabetic nephropathy, including AER and estimated GFR. No associations were found between the SNPs and cardiovascular disease, blood pressure, serum lipid levels or type 1 diabetes.

Conclusions/interpretation The common SNPs tested in DDOST, PRKCSH and LGALS3 do not seem to be associated with diabetic micro- or macrovascular complications or with type 1 diabetes in Finnish patients.

Keywords Advanced glycation end-product receptor . Cardiovascular disease - DDOST - Diabetic nephropathy . Genetic association $\cdot L G A L S 3 \cdot P R K C S H \cdot$ SNP

\begin{tabular}{|c|c|}
\hline \multicolumn{2}{|c|}{ Abbreviations } \\
\hline AGE-R & AGE receptor \\
\hline CEU & $\begin{array}{l}\text { Centre d'Etude du Polymorphisme (Utah } \\
\text { residents with northern and western European } \\
\text { ancestry) }\end{array}$ \\
\hline ESRD & End-stage renal disease \\
\hline FinnDiane & Finnish Diabetic Nephropathy Study \\
\hline HWE & Hardy-Weinberg equilibrium \\
\hline LD & Linkage disequilibrium \\
\hline MAF & Minor allele frequency \\
\hline RAGE & AGE-R protein \\
\hline SNP & Single nucleotide polymorphism \\
\hline
\end{tabular}




\section{Introduction}

In patients with diabetes, chronic hyperglycaemia causes increased formation and accumulation of AGEs, which are involved in the pathogenesis of diabetic nephropathy, retinopathy and cardiovascular disease. Although AGEs have adverse effects on their own (e.g. via cross-linking of proteins), much of their harmful effect is mediated via specific AGE receptors (AGE-Rs). On the other hand, some AGE-Rs have beneficial effects and contribute to clearance of AGEs from the circulation [1].

The AGER gene on chromosome $6 \mathrm{p} 21$ encodes the receptor for AGEs (RAGE). We have previously shown that the functional single nucleotide polymorphism (SNP) $-374 \mathrm{~T} / \mathrm{A}$ (rs1800624) in the promoter region of $A G E R$ is associated with cardiovascular disease in Finnish patients with type 1 diabetes and with proteinuria in patients with poor glycaemic control [2]. Subsequent studies have shown that $A G E R$ is associated with diabetic nephropathy in white patients with type 1 diabetes [3, 4] and with sight-threatening diabetic retinopathy in type 1 diabetes patients [4].

In this study, we tested three other AGE-R genes for association with diabetic nephropathy, cardiovascular disease, blood pressure, serum lipid levels and type 1 diabetes in Finnish patients. The genes tested were: (1) DDOST (located on chromosome 1p36.12), which encodes AGER1; (2) PRKCSH (chromosome 19p13.2), which encodes AGE-R2; and (3) LGALS3 (chromosome 14q22.3), which encodes AGE-R3.

\section{Methods}

Participants We recruited 2,719 unrelated Finnish individuals with type 1 diabetes mellitus (Table 1) from the Finnish Diabetic Nephropathy (FinnDiane) Study. The study was approved by the Ethics Committees of each participating centre. Written informed consent was obtained from all the patients. We also genotyped 703 non-diabetic control participants recruited from all over Finland for association analysis with type 1 diabetes. The blood samples from these participants were collected by the Finnish Red Cross Blood Transfusion Service and information on age, sex and place of blood donation was available.

The diagnosis of type 1 diabetes mellitus was based on an age at onset of diabetes of less than 35 years and permanent insulin treatment initiated within 1 year of the diagnosis. The renal status was determined on the basis of AER in at least two out of three consecutive 24-h or overnight urine collections. Normal AER was defined as AER $<30 \mathrm{mg} / 24 \mathrm{~h}$ or $<20 \mu \mathrm{g} / \mathrm{min}$. For association analysis with diabetic nephropathy, patients with normal AER (i.e. controls) were required to have diabetes duration of at least 15 years to ensure their renal status $(n=1060)$. Microalbuminuria was defined as AER $\geq 30$ and $<300 \mathrm{mg} / 24 \mathrm{~h}$, or $\geq 20$ and $<200 \mu \mathrm{g} / \mathrm{min}$; macroalbuminuria was defined as AER $\geq 300 \mathrm{mg} / 24 \mathrm{~h}$ or $\geq 200 \mu \mathrm{g} / \mathrm{min}$. End-stage renal disease (ESRD) patients were either on dialysis treatment or had received a kidney transplant. Diabetic nephropathy was defined as having either macroalbuminuria or ESRD (cases).

Table 1 Clinical characteristics of the patients with type 1 diabetes

\begin{tabular}{|c|c|c|c|c|}
\hline Characteristics & Normal AER & Micro-albuminuria & Macro-albuminuria & ESRD \\
\hline$n$ & 1,444 & 454 & 554 & 267 \\
\hline Men (\%) & 46 & 59 & 59 & 61 \\
\hline Age (years) & $37.9 \pm 12.0$ & $39.9 \pm 12.3$ & $41.4 \pm 10.4$ & $44.1 \pm 8.0$ \\
\hline Age at diabetes onset (years) & $15.0 \pm 8.4$ & $13.8 \pm 10.3$ & $12.4 \pm 8.5$ & $11.5 \pm 6.8$ \\
\hline Time to DN (years) ${ }^{\mathrm{a}}$ & & & $19.5 \pm 7.9$ & $19.9 \pm 7.3$ \\
\hline BMI $\left(\mathrm{kg} / \mathrm{m}^{2}\right)$ & $24.8 \pm 3.2$ & $25.9 \pm 3.7$ & $25.8 \pm 3.9$ & $24.0 \pm 3.6$ \\
\hline Systolic BP (mmHg) & $130 \pm 16$ & $136 \pm 17$ & $145 \pm 20$ & $153 \pm 23$ \\
\hline Diastolic BP (mmHg) & $78 \pm 9$ & $81 \pm 10$ & $83 \pm 10$ & $86 \pm 12$ \\
\hline $\mathrm{HbA}_{1 \mathrm{c}}(\%)$ & $8.3 \pm 1.3$ & $8.8 \pm 1.4$ & $9.1 \pm 1.6$ & $8.6 \pm 1.5$ \\
\hline $\operatorname{AER}(m g / 24 \quad h)$ & $8(5-13)$ & $58(26-112)$ & $498(173-1311)$ & - \\
\hline Estimated GFR (ml $\left.\min ^{-1} 1.73 \mathrm{~m}^{-2}\right)$ & $97 \pm 22$ & $93 \pm 25$ & $64 \pm 32$ & - \\
\hline Serum creatinine $(\mu \mathrm{mol} / \mathrm{l})$ & $83(74-92)$ & $89(79-101)$ & $126(96-182)$ & - \\
\hline Total cholesterol (mmol/l) & $4.8 \pm 0.9$ & $5.0 \pm 0.9$ & $5.4 \pm 1.1$ & $5.4 \pm 1.2$ \\
\hline HDL-cholesterol (mmol/l) & $1.4 \pm 0.4$ & $1.3 \pm 0.4$ & $1.2 \pm 0.4$ & $1.1 \pm 0.4$ \\
\hline Triacylglycerol (mmol/l) & $1.1 \pm 0.7$ & $1.3 \pm 0.9$ & $1.8 \pm 1.2$ & $1.8 \pm 0.9$ \\
\hline
\end{tabular}

Values are mean $\pm \mathrm{SD}$ or median (interquartile range), unless otherwise indicated

${ }^{\mathrm{a}} \mathrm{DN}$; time from diagnosis of type 1 diabetes to diagnosis of diabetic nephropathy 
Comprehensive data on each patient's medical history and lifestyle were collected with a standardised questionnaire, which was completed by the attending physician based upon medical files and a clinical examination. Serum $\mathrm{HbA}_{1 \mathrm{c}}$, creatinine, triacylglycerol and lipoproteins were centrally measured using standard laboratory methods. Estimated GFR was calculated using the Cockcroft-Gault formula [5] adjusted for body surface area. Cardiovascular disease was defined as a history of any of the following events: acute myocardial infarction, coronary artery bypass surgery, peripheral artery bypass surgery, stroke or amputation.

SNPs and genotyping The selection of SNPs was based on HapMap data (www.hapmap.org, accessed 27 April 2006) on the Centre d'Etude du Polymorphisme (Utah residents with northern and western European ancestry) (CEU) population. The SNPs capturing common variants (minor allele frequency $[\mathrm{MAF}] \geq 5 \%$ ) were selected using the Tagger program (www.broad.mit.edu/mpg/tagger/, accessed 27 April 2006). Thirteen SNPs were selected for DDOST ( $\sim 1 \mathrm{~kb}$ upstream and $\sim 10 \mathrm{~kb}$ downstream), nine for PRKCSH ( $\sim 10 \mathrm{~kb}$ upstream and $\sim 13 \mathrm{~kb}$ downstream) and six for LGALS3 ( $\sim 9 \mathrm{~kb}$ upstream and $\sim 2 \mathrm{~kb}$ downstream; Electronic supplementary material [ESM] Table 1).

The SNPs were genotyped using TaqMan chemistry and a sequence detection system (ABI Prism 7900; Applied Biosystems, Foster City, CA, USA) in a single SNP format or a mass array system (Homogenous MassExtend MassArray System; Sequenom, San Diego, CA, USA) in a multiplex format. These genotyping methods are robust and quality of genotyping was further ensured by requiring complete accuracy for the DNA and non-template controls. Genotyping success rates varied between $96 \%$ and $100 \%$, except for the PRKCSH SNP rs34099, which was excluded.

Statistical analyses Genotype distributions were tested separately for Hardy-Weinberg equilibrium (HWE) in the non-diabetic controls and in the patients with type 1 diabetes mellitus. Haploview 3.2 (www.broad.mit.edu/ mpg/haploview/, accessed 1 January 2009) was used to estimate linkage disequilibrium (LD; $r^{2}$ and $D^{\prime}$ ) between the SNPs. Haplotype blocks were constructed using the confidence interval algorithm implemented in Haploview. Allele and genotype association analyses for diabetic nephropathy, cardiovascular disease and type 1 diabetes were performed using the $\chi^{2}$ test. Associations with quantitative traits were analysed in all patients with normal AER, microalbuminuria or macroalbuminuria using oneway ANOVA or the non-parametric Kruskal-Wallis test. SPSS 16.0 for Windows (SPSS, Chicago, IL, USA) was used for the analyses.

As a correction for multiple testing, a significance limit of 0.0008 was calculated by dividing 0.05 with the number of independent SNPs and variables tested for association (for details, see ESM 1). Our sample size reached a statistical power of $98 \%(p=0.05)$ to detect an association between a common SNP and diabetic nephropathy (for details, see ESM 1).

\section{Results}

All the SNPs were in HWE $(p>0.001)$ in non-diabetic control participants (ESM Table 1) except for rs 11557488 in PRKCSH, which was thus excluded from further analyses. The SNPs were also in HWE in the patients with type 1 diabetes. There was $\sim 1 \mathrm{SNP} / 0.75 \mathrm{~kb}$ in DDOST, $\sim 1$ $\mathrm{SNP} / 2.2 \mathrm{~kb}$ in PRKCSH and $\sim 1 \mathrm{SNP} / 2.7 \mathrm{~kb}$ in LGALS3. MAFs varied between 0.03 and 0.49 in the non-diabetic controls (ESM Table 1). ESM Fig. 1 shows the locations of the studied SNPs and LD between the SNPs in the Finnish non-diabetic control participants.

We found evidence of genotype association between diabetic nephropathy and the DDOST SNP rs2170336 ( $p=$ 0.03 , Table 2), and of allele and genotype association between diabetic nephropathy and the PRKCSH SNPs $\operatorname{rs} 311788(p=0.03 ; p=0.04)$ and $\operatorname{rs} 311778(p=0.01 ; p=$ 0.02). However, these associations did not reach the significance limit of 0.0008 adjusted for multiple testing.

We also tested quantitative variables (estimated GFR and AER) related to diabetic nephropathy, but no associations were found (data not shown). We also failed to find any association between the SNPs and cardiovascular disease (ESM Table 2), blood pressure (ESM Table 3), serum lipid levels (total cholesterol, HDL-cholesterol, LDL-cholesterol, triacylglycerol; ESM Table 4) or type 1 diabetes (ESM Table 5).

\section{Discussion}

This study suggests that the common SNPs tested by us in DDOST, PRKCSH and LGALS3 are not associated with diabetic nephropathy or related quantitative traits, cardiovascular disease, blood pressure, serum lipid levels or type 1 diabetes in Finnish patients.

Our study sample consisted of Finnish patients with type 1 diabetes recruited nationwide by the FinnDiane Study. It provides an excellent sample to identify genetic factors in diabetic nephropathy. The sample was reasonably large, with a statistical power of $98 \%$ to detect an association between a common genetic variant and diabetic nephropathy. Another strength of this study is that the SNPs genotyped provide reasonable coverage of the common variants in the studied genes. We selected the SNPs on the basis of HapMap CEU data, which have previously been shown to be suitable for 
Table 2 Allele and genotype frequencies for the DDOST, PRKCSH and LGALS3 SNPs

\begin{tabular}{|c|c|c|c|c|c|c|c|c|c|c|c|c|c|}
\hline \multirow[t]{3}{*}{ SNP } & \multirow[t]{3}{*}{ Alleles } & \multicolumn{5}{|c|}{ Allele frequencies } & \multicolumn{7}{|c|}{ Genotype frequencies } \\
\hline & & \multicolumn{2}{|c|}{ No nephropathy ${ }^{\mathrm{a}}$} & \multicolumn{2}{|c|}{ With nephropathy ${ }^{\mathrm{b}}$} & \multirow[t]{2}{*}{$p$ value $^{\mathrm{c}}$} & \multicolumn{3}{|c|}{ No nephropathy ${ }^{\mathrm{a}}$} & \multicolumn{3}{|c|}{ With nephropathy ${ }^{\mathrm{b}}$} & \multirow[t]{2}{*}{$p$ value $^{\mathrm{c}}$} \\
\hline & & 1 & 2 & 1 & 2 & & 11 & 12 & 22 & 11 & 12 & 22 & \\
\hline \multicolumn{14}{|l|}{$D D O S T$} \\
\hline rs 12569006 & $\mathrm{~A} / \mathrm{T}$ & 0.80 & 0.20 & 0.81 & 0.19 & 0.21 & 0.63 & 0.33 & 0.04 & 0.66 & 0.32 & 0.03 & 0.40 \\
\hline rs10157351 & $\mathrm{G} / \mathrm{T}$ & 0.41 & 0.59 & 0.41 & 0.59 & 0.87 & 0.17 & 0.50 & 0.34 & 0.17 & 0.49 & 0.34 & 0.98 \\
\hline rs 1570663 & $\mathrm{G} / \mathrm{T}$ & 0.19 & 0.81 & 0.19 & 0.81 & 0.92 & 0.04 & 0.30 & 0.66 & 0.04 & 0.30 & 0.67 & 0.93 \\
\hline rs 2170336 & $\mathrm{C} / \mathrm{T}$ & 0.16 & 0.84 & 0.17 & 0.83 & 0.71 & 0.04 & 0.26 & 0.71 & 0.02 & 0.30 & 0.68 & 0.03 \\
\hline rs3818392 & $\mathrm{A} / \mathrm{G}$ & 0.40 & 0.60 & 0.41 & 0.59 & 0.40 & 0.17 & 0.46 & 0.37 & 0.16 & 0.51 & 0.34 & 0.17 \\
\hline rs631357 & $\mathrm{C} / \mathrm{G}$ & 0.78 & 0.22 & 0.80 & 0.20 & 0.39 & 0.61 & 0.34 & 0.05 & 0.63 & 0.33 & 0.04 & 0.69 \\
\hline rs10916846 & $\mathrm{C} / \mathrm{T}$ & 0.06 & 0.94 & 0.07 & 0.93 & 0.94 & 0.01 & 0.12 & 0.88 & 0.01 & 0.12 & 0.88 & 0.98 \\
\hline rs640742 & $\mathrm{G} / \mathrm{T}$ & 0.61 & 0.39 & 0.62 & 0.38 & 0.86 & 0.37 & 0.49 & 0.14 & 0.37 & 0.49 & 0.14 & 0.96 \\
\hline rs10799658 & $\mathrm{C} / \mathrm{T}$ & 0.65 & 0.35 & 0.65 & 0.35 & 0.82 & 0.44 & 0.43 & 0.13 & 0.42 & 0.47 & 0.12 & 0.33 \\
\hline rs 4704 & $\mathrm{C} / \mathrm{T}$ & 0.62 & 0.38 & 0.62 & 0.38 & 1.00 & 0.39 & 0.46 & 0.15 & 0.39 & 0.46 & 0.15 & 0.99 \\
\hline rs 2070658 & $\mathrm{C} / \mathrm{T}$ & 0.09 & 0.91 & 0.08 & 0.92 & 0.48 & 0.01 & 0.15 & 0.84 & 0.01 & 0.15 & 0.85 & 0.59 \\
\hline rs 2070660 & $\mathrm{~A} / \mathrm{C}$ & 0.76 & 0.24 & 0.76 & 0.24 & 0.83 & 0.59 & 0.34 & 0.06 & 0.58 & 0.37 & 0.05 & 0.41 \\
\hline rs686658 & $\mathrm{A} / \mathrm{T}$ & 0.09 & 0.91 & 0.09 & 0.91 & 0.88 & 0.01 & 0.16 & 0.82 & 0.01 & 0.16 & 0.83 & 0.99 \\
\hline \multicolumn{14}{|l|}{ PRKCSH } \\
\hline rs501257 & $\mathrm{C} / \mathrm{T}$ & 0.15 & 0.85 & 0.16 & 0.84 & 0.10 & 0.02 & 0.26 & 0.72 & 0.02 & 0.27 & 0.71 & 0.75 \\
\hline rs34100 & $\mathrm{A} / \mathrm{G}$ & 0.96 & 0.04 & 0.96 & 0.04 & 0.41 & 0.92 & 0.08 & 0.00 & 0.93 & 0.07 & 0.00 & 0.65 \\
\hline rs34088 & $\mathrm{C} / \mathrm{T}$ & 0.11 & 0.89 & 0.11 & 0.89 & 0.39 & 0.01 & 0.19 & 0.80 & 0.01 & 0.21 & 0.78 & 0.62 \\
\hline rs313624 & $\mathrm{C} / \mathrm{T}$ & 0.59 & 0.41 & 0.56 & 0.44 & 0.06 & 0.20 & 0.48 & 0.32 & 0.19 & 0.45 & 0.37 & 0.13 \\
\hline rs 160840 & $\mathrm{~A} / \mathrm{G}$ & 0.07 & 0.93 & 0.08 & 0.92 & 0.59 & 0.01 & 0.13 & 0.86 & 0.01 & 0.14 & 0.86 & 0.74 \\
\hline rs311788 & $\mathrm{A} / \mathrm{T}$ & 0.93 & 0.07 & 0.95 & 0.05 & 0.03 & 0.86 & 0.14 & 0.00 & 0.89 & 0.11 & 0.00 & 0.04 \\
\hline rs311778 & $\mathrm{C} / \mathrm{G}$ & 0.93 & 0.07 & 0.95 & 0.05 & 0.01 & 0.85 & 0.14 & 0.00 & 0.89 & 0.11 & 0.00 & 0.02 \\
\hline \multicolumn{14}{|l|}{$L G A L S 3$} \\
\hline rs8007614 & $\mathrm{C} / \mathrm{T}$ & 0.51 & 0.49 & 0.51 & 0.49 & 0.83 & 0.26 & 0.51 & 0.23 & 0.27 & 0.49 & 0.25 & 0.67 \\
\hline rs3825613 & $\mathrm{A} / \mathrm{C}$ & 0.49 & 0.51 & 0.50 & 0.50 & 0.71 & 0.24 & 0.51 & 0.26 & 0.25 & 0.49 & 0.26 & 0.71 \\
\hline rs1009977 & $\mathrm{G} / \mathrm{T}$ & 0.51 & 0.49 & 0.51 & 0.49 & 0.91 & 0.26 & 0.51 & 0.23 & 0.27 & 0.49 & 0.24 & 0.78 \\
\hline rs 4644 & $\mathrm{~A} / \mathrm{C}$ & 0.49 & 0.51 & 0.50 & 0.50 & 0.54 & 0.26 & 0.50 & 0.24 & 0.26 & 0.49 & 0.25 & 0.67 \\
\hline rs 10498475 & $\mathrm{C} / \mathrm{T}$ & 0.93 & 0.07 & 0.93 & 0.07 & 0.42 & 0.87 & 0.13 & 0.00 & 0.86 & 0.14 & 0.00 & 0.66 \\
\hline rs2274273 & $\mathrm{C} / \mathrm{T}$ & 0.51 & 0.49 & 0.50 & 0.50 & 0.75 & 0.26 & 0.50 & 0.24 & 0.26 & 0.49 & 0.25 & 0.83 \\
\hline
\end{tabular}

Alleles: 1 denotes the first allele, 2 denotes the second allele

${ }^{\mathrm{a}} n=1,060 ;{ }^{\mathrm{b}} n=821 ;{ }^{\mathrm{c}}$ for association with diabetic nephropathy

selecting tag SNPs in the Finnish population [6]. The pairwise LD observed for the common SNPs genotyped in the Finnish non-diabetic participants in our study was similar to the LD observed for the same SNPs in the DDOST, PRKCSH and LGALS3 genes in the HapMap CEU data. A limitation of our study is that potential rare susceptibility variants and variants with small effect sizes or located far away from the studied genes went undetected.

Despite the potential implication of the studied AGE-R genes in the pathogenesis of diabetic complications, only one association study of these genes has been published so far. In that study by Poirier et al., evidence of nominal association $(p=0.041)$ between the glutamic acid repeats in
PRKCSH and diabetic nephropathy was detected in a sample of 199 cases and 193 controls [7]. We analysed PRKCSH in a larger sample set and using a denser set of markers, but found no association with diabetic nephropathy.

Several previous findings provide the basis for ranking DDOST, PRKCSH and LGALS3 as relevant candidate genes for diabetic complications. First, the $A G E R$ gene encoding RAGE has been associated with cardiovascular disease [2], proteinuria [2-4] and retinopathy [4] in patients with type 1 diabetes. Second, AGE-R1, which is encoded by DDOST, enhances the clearance of AGEs from the circulation [8], while diabetic nephropathy in patients with type 1 diabetes has been associated with low levels of AGE-R1 in 
circulating mononuclear cells and with elevated levels of serum AGEs [9]. Moreover, an increased amount of AGER1 suppresses AGE-mediated mesangial cell inflammatory injury through negative regulation of RAGE signalling [10]. AGE-R3, which is encoded by $L G A L S 3$, also seems to participate in the degradation of AGEs, since knockout mice for AGE-R3 have higher AGE levels in the kidneys and a higher incidence of age-related glomerular lesions [11].

The clustering of genetic risk factors for many autoimmune diseases suggests that these diseases share similar underlying causal mechanisms [12]. Combining genomewide association data on type 1 diabetes with those on other autoimmune diseases may help to identify additional genetic risk factors [12]. The role of rare or structural genetic variations in the development of type 1 diabetes and diabetic nephropathy should also be studied.

In summary, we found no evidence of association between the common variants studied by us in DDOST, PRKCSH or $L G A L S 3$ and diabetic nephropathy or other diabetic complications in Finnish patients with type 1 diabetes.

Acknowledgements We warmly thank all patients participating in the FinnDiane Study. We acknowledge the assistance of the FinnDiane Study Group [13] and, especially, the skilled technical assistance of S. Lindh and A. Sandelin. SNP genotyping based on Sequenom technology was performed at the Finnish Genome Center. This study was funded by the Sigrid Juselius Foundation, the Academy of Finland (grant nos 214335 and 124280 to M. Wessman), the Diabetes Research Foundation (funds to M. Wessman), Folkhälsan Research Foundation, the Research Funds of the Helsinki University Central Hospital, the Wilhelm and Else Stockmann Foundation, and Medicinska Understödsföreningen Liv och Hälsa r.f.

Duality of interest The authors declare that there is no duality of interest associated with this manuscript.

Open Access This article is distributed under the terms of the Creative Commons Attribution Noncommercial License which permits any noncommercial use, distribution, and reproduction in any medium, provided the original author(s) and source are credited.

\section{References}

1. Ahmed N (2005) Advanced glycation endproducts-role in pathology of diabetic complications. Diab Res Clin Pract 67:321

2. Pettersson-Fernholm K, Forsblom C, Hudson BI et al (2003) The functional -374T/A RAGE gene polymorphism is associated with proteinuria and cardiovascular disease in type 1 diabetic patients. Diabetes 52:891-894

3. Prevost G, Fajardy I, Besmond C et al (2005) Polymorphisms of the receptor of advanced glycation endproducts (RAGE) and the development of nephropathy in type 1 diabetic patients. Diab Metab 31:35-39

4. Lindholm E, Bakhtadze E, Sjogren M et al (2006) The -374T/A polymorphism in the gene encoding RAGE is associated with diabetic nephropathy and retinopathy in type 1 diabetic patients. Diabetologia 49:2745-2755

5. Cockcroft DW, Gault MH (1976) Prediction of creatinine clearance from serum creatinine. Nephron 16:31-41

6. Lundmark PE, Liljedahl U, Boomsma D et al (2008) Evaluation of HapMap data in six populations of European descent. Eur $\mathbf{J}$ Hum Genet 16:1142-1150

7. Poirier O, Nicaud V, Vionnet N et al (2001) Polymorphism screening of four genes encoding advanced glycation end-product putative receptors. Association study with nephropathy in type 1 diabetic patients. Diabetes 50:1214-1218

8. Vlassara H, Brownlee M, Cerami A (1985) High-affinity-receptormediated uptake and degradation of glucose-modified proteins: a potential mechanism for the removal of senescent macromolecules. Proc Natl Acad Sci USA 82:5588-5592

9. He CJ, Koschinsky T, Buenting C, Vlassara H (2001) Presence of diabetic complications in type 1 diabetic patients correlates with low expression of mononuclear cell AGE-receptor-1 and elevated serum AGE. Mol Med 7:159-168

10. Lu C, He JC, Cai W, Liu H, Zhu L, Vlassara H (2004) Advanced glycation endproduct (AGE) receptor 1 is a negative regulator of the inflammatory response to AGE in mesangial cells. Proc Natl Acad Sci U S A 101:11767-11772

11. Iacobini C, Menini S, Oddi G et al (2004) Galectin-3/AGEreceptor 3 knockout mice show accelerated AGE-induced glomerular injury: evidence for a protective role of galectin-3 as an AGE receptor. FASEB J 18:1773-1775

12. Lettre G, Rioux JD (2008) Autoimmune diseases: insights from genome-wide association studies. Hum Mol Genet 17:R116-R121

13. Saraheimo M, Forsblom C, Thorn L et al (2008) Serum adiponectin and progression of diabetic nephropathy in patients with type 1 diabetes. Diab Care 31:1165-1169 